\title{
Longitudinal Study of a Newborn with a Combination of Deletion and Nondeletion $\alpha$-Thalassemia-2
}

\author{
R. GALANEllo, M. A. MElis, L. MACCIONI, M. PIRASTU, ${ }^{(24)}$ AND A. CAO ${ }^{(26)}$ \\ Institute of Clinic and Biology of Developmental Age, Cagliari University, Sardinia, Italy
}

\begin{abstract}
Summary
In this study we have characterized by DNA analysis the molecular basis of an $\alpha$-thalassemia condition found in an infant, with $16 \% \mathrm{Hb}$ Bart's at birth, who developed an hematologic picture similar to the $\alpha$-thalassemia carrier state. Restriction endonuclease analysis and hybridization with $\alpha$ and $\zeta$ specific probes have provided strong evidence that this patient carries a genetic compound of deletion $\alpha$-thalassemia-2 lesion $(-\alpha)$ and a non-deletion defect $\left\{(\alpha \alpha)^{\text {th }}\right\}$ with both $\alpha$-structural genes intact on chromosome 16. He inherited the deletion $\alpha$-thalassemia-2 chromosome $(-\alpha)$ from the father and the chromosome with nondeletion $\alpha$-thalassemia defect from the mother. Because the deletion of one, two, or three $\alpha$-globin structural genes is associated with $1-2 \%, 5-6 \%$, or $25 \%$, Hb Bart's respectively, these findings suggest that the non-deletion chromosome $\left\{(\alpha \alpha)^{\text {th }}\right\}$ contains two $\alpha$-globin structural genes that are less active than a single $\alpha$ gene $(-\alpha)$.
\end{abstract}

\section{Abbreviations}

Hb, hemoglobin

$\mathrm{HbH}$, hemoglobin $\mathbf{H}$

$\mathrm{Kb}$, kilobases

MED, Mediterranean patients

MCH, mean corpuscular hemoglobin

$\mathrm{MCV}$, mean corpuscular volume

$\mathrm{RBC}$, red blood cell

SEA, South East Asian patients

The duplicated human $\alpha$-globin structural genes are linked to one $\zeta$-globin gene, an $\alpha$-like $\left(\psi \alpha_{1}\right)$ and a $\zeta$-like $\left(\psi \zeta_{1}\right)$ pseudogenes within a $21 \mathrm{~Kb}$ region of DNA on chromosome 16 , in the order $5^{\prime}-\zeta-\psi \zeta-\psi \alpha_{1}-\alpha_{2}-\alpha_{1}-3^{\prime}(9,20)$.

Several different mutations involving this gene complex produce the $\alpha$-thalassemia syndromes. These mutations can be divided into two groups: one characterized by no $\alpha$-globin chain production ( $\alpha$-thalassemia-1 genotypes) and the other by a reduced output of $\alpha$-globin chains ( $\alpha$-thalassemia-2 genotypes)
(22).

Different combinations of these two groups of defects produce the four clinical states of $\alpha$-thalassemia. The silent carrier state is due to heterozygosity of $\alpha$-thalassemia-2; $\alpha$-thalassemia trait is caused either by heterozygosity of $\alpha$-thalassemia- 1 or by homozygosity of $\alpha$-thalassemia-2; HbH disease is produced by compound heterozygosity for $\alpha$-thalassemia- 1 and $\alpha$-thalassemia-2; the homozygous state of $\alpha$-thalassemia- 1 results in fetal hydrops.

The molecular basis of the $\alpha$-thalassemia phenotype is very heterogeneous. Most commonly the lesions causing $\alpha$-thalassemia- 1 and $\alpha$-thalassemia- 2 result from deletion of both (- -) or one $(-\alpha)$ of the duplicated $\alpha$-globin structural loci respectively ( 1 $13,15,18,19)$. Less frequently $\alpha$-thalassemia- 2 is produced by non-deletion defects $\left\{(\alpha \alpha)^{\text {th }}\right\}(3,5,8,14,16)$.

Hemoglobin Bart's $>1 \%$ at birth is the expression of a deficiency of $\alpha$-chain production and thus reflects the presence of $\alpha$ thalassemia (22). Restriction endonuclease analysis in infants with different levels of Hb Bart's at birth have clearly shown, in both Negro and South Asian populations, that subjects with 1$2 \% \mathrm{Hb}$ Bart's have one $\alpha$-globin structural gene deleted $(-\alpha)$, those with $5-6 \%$ have the deletion of two $\alpha$-globin $(-\alpha /-\alpha$ or --1 $\alpha \alpha)$ structural genes and those with $25 \%$ have three $\alpha$-genes deleted $(-\alpha /--)(4,10,12)$.

In a survey of newborn Sardinian infants, besides subjects having the above mentioned levels, we found rare individuals with about $16 \%$ hemoglobin Bart's (2). In this paper we report $\alpha$-globin structural gene analysis and a follow-up study of one of these infants. Our findings indicate that this subject is a double heterozygote for the deletion form $\alpha$-thalassemia- $2(-\alpha)$ and a non-deletion $\alpha$-thalassemia lesion $\left\{(\alpha \alpha)^{\text {th }}\right\}$. This gene combination produces, especially in the neonatal period, a slightly more severe hematologic phenotype than that of homozygous deletion $\alpha$-thalassemia-2 $(-\alpha /-\alpha)$, but much less severe than that resulting from $\mathrm{HbH}$ disease $(-\alpha /--)$.

Case report. The subject studied (M. L.) was identified in a newborn screening for abnormal hemoglobins carried out in Southern Sardinia (2). He was regularly followed in our outpatient service from birth till 2.5 years.

In the neonatal period he developed jaundice with a peak bilirubin level of $15.5 \mathrm{mg} \%$ at 3 days. He received an iron fortified formula. Solid foods (milk, flour, and vegetables) were first introduced at 3 months. This diet was supplemented with all vitamins, including folic acid.

At 2.5 years his height was $92 \mathrm{~cm}(50-75$ th percentile) and his weight $13 \mathrm{~kg}$ (50th percentile).

Physical examination was unremarkable. In particular there was no liver and spleen enlargement.

As controls, we followed also eight children with no $\mathrm{Hb}$ Bart's at birth and a normal $\alpha$-globin genotype, six children with intermediate levels of $\mathrm{Hb}$ Bart's at birth $(3.0-7.03 \%)$ and a $(-\alpha /-\alpha) \alpha$-globin genotype and one child with the $(-\alpha /--)$ genotype who developed $\mathrm{HbH}$ disease.

\section{MATERIALS AND METHODS}

Red blood cell indices were obtained with Coulter Counter model S daily standardized with $4 \mathrm{C}$ Commercial standard. The quantitation of $\mathrm{Hb}$ Bart's was performed in duplicate by elution of cellulose acetate strips after electrophoresis in phosphate system buffer pH $6.5(22)$.

Hemoglobin $\mathrm{A}_{2}$ was quantified by column microchromatog- 
raphy (6). Globin chain synthesis analysis was performed according to Kan et al. (7). DNA prepared from white blood cells by phenol-chloroform isoamyl alcohol extraction and ethanol precipitation was digested with restriction endonucleases $\mathrm{Bam} \mathrm{HI}$ and $B g l$ II (Boehringer Mannheim, West Germany) for $24 \mathrm{~h}$ in the appropriate buffer. After electrophoresis in $0.8 \%$ agarose gel the DNA fragments were transferred to a nitrocellulose filter by the gel blotting technique of Southern (21). The filters were hybridized with specific $\left[{ }^{32} \mathrm{P}\right]$-labeled $\alpha$-globin CDNA probe prepared by nick-translation from $\alpha$-globin gene cloned in plasmid JW-101 $(11,23)$, and with a $\zeta$-specific probe prepared by nicktranslation of Hinf I fragment of $\mathrm{pBR} \zeta$ plasmid (9).

\section{RESULTS}

Hematologic and hemoglobin analysis. At birth the infant presented a thalassemia-like hematologic syndrome with increased red blood cell count, almost normal Hb levels, very low
MCV and MCH and Hb Bart's about 16\% (Table 1). Globin chain synthesis analysis showed a slight imbalance of $\alpha /$ non $\alpha$ ratio $(0.78)$

Hematologic follow-up is shown in Figure 1. As can be seen, he developed moderate hypochromic anemia with nadir of $\mathrm{Hb}$ level at 45 days, followed by a gradual increase till values around $11 \mathrm{~g} \%$ at 8 months. $\mathrm{MCH}$ values showed a progressive reduction till 4.5 months, when they levelled around $19 \mathrm{pg}$. MCV values decreased more slowly with a nadir at 5.5 months followed by a plateau at approximately $58 \mathrm{fl}$. Hb Bart's levels gradually decreased, becoming undetectable at 1 year. The developmental pattern of $\mathrm{Hb} \mathrm{F}$ was similar to that seen in normal infants.

Apart from a transient increase above the normal range at 3 months, $\mathrm{Hb} \mathrm{A}_{2}$ levels were lower than in normal infants in all the follow-up period until 2 years. Later on, there was a continuous gradual increase with attainment of normal values $(2.7 \%)$ at $2 \frac{1}{2}$ years of age.

Zinc-protoporphyrin and transferrin saturation were always

Table 1. Hematologic data of the propositus and his parents

\begin{tabular}{|c|c|c|c|c|c|c|c|}
\hline & $\begin{array}{c}\mathrm{RBC}^{*} \\
\left(\times 10^{12} / \text { liter }\right)\end{array}$ & $\begin{array}{l}\mathrm{Hb}^{*} \\
(\mathrm{~g} / \mathrm{dl})\end{array}$ & $\begin{array}{c}\mathrm{MCV}^{*} \\
(\mathrm{fl})\end{array}$ & $\begin{array}{c}\mathrm{MCH}^{*} \\
(\mathrm{pg})\end{array}$ & $\begin{array}{c}\mathrm{Hb} \mathrm{A}{ }_{2} \\
(\%)\end{array}$ & $\begin{array}{c}\text { Hb Bart's } \\
(\%)\end{array}$ & $\begin{array}{c}\alpha / \text { non- } \alpha \\
\text { ratio }\end{array}$ \\
\hline M.L. at birth & 6.5 & 17.4 & 79 & 26.4 & 0.28 & 15.4 & 0.78 \\
\hline M.L. at 2 yr & 5.39 & 10.8 & 61 & 20.5 & 2.02 & & \\
\hline Father & 5.05 & 14.7 & 87 & 29.9 & 1.78 & & 0.78 \\
\hline Mother & 4.18 & 13.1 & 86 & 32.2 & 2.11 & & 0.88 \\
\hline Normal newborn & $5.12 \pm 0.76$ & $18.1 \pm 2.3$ & $101.3 \pm 6.9$ & $35.1 \pm 3.5$ & $0.38 \pm 0.16$ & & \\
\hline Normal children at $2 \mathrm{yr}$ & $4.80 \pm 0.40$ & $12.7 \pm 0.9$ & $75.6 \pm 4.0$ & $26.4 \pm 2.3$ & $2.50 \pm 0.31$ & & \\
\hline Normal adult males & $5.18 \pm 0.40$ & $15.9 \pm 1.03$ & $89.1 \pm 5.08$ & $30.9 \pm 1.94$ & $2.55 \pm 0.22$ & & \\
\hline Normal adult females & $4.69 \pm 0.43$ & $14.0 \pm 0.90$ & $87.6 \pm 5.50$ & $30.2 \pm 2.14$ & $2.52 \pm 0.26$ & & \\
\hline
\end{tabular}

* Abbreviations: RBC, red blood cell; Hb, hemoglobin; MCV, mean corpuscular volume; MCH, mean corpuscular hemoglobin.
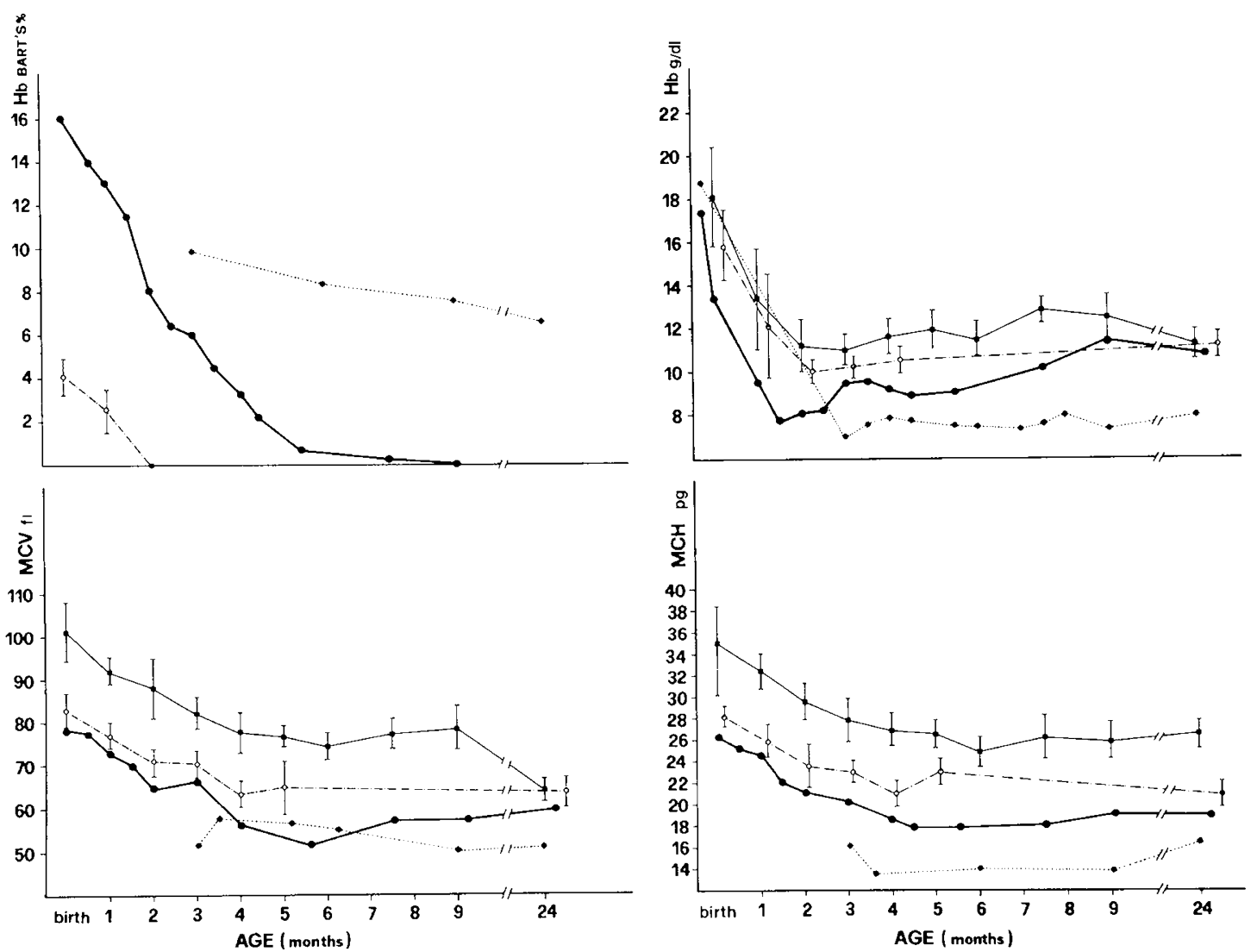

Fig. 1. A longitudinal study of hematologic findings observed in our patient M. L. intermediate levels of $\mathrm{Hb}$ Bart's $(\mathrm{OOO})$ and a subject with $\mathrm{HbH}$ disease $(* \cdots \cdots *)$. 
within the normal range ( $20 \%$ at 6 months and $23 \%$ at 2 years).

At 2.5 years $\alpha / \beta$ globin chain synthesis ratio was 0.86 , which is within the $\alpha$-thalassemia- 2 carrier range $(0.62-0.88)$.

The hematologic changes of our patient were slightly more severe than those seen in homozygotes for the deletion $\alpha$-thalassemia-2 lesion $(-\alpha /-\alpha)$, but much less severe than that resulting from $\mathrm{HbH}$ disease, either with the deletion form $(-\alpha /--)$ or with combination of non-deletion and deletion lesions $\left\{\left(--/(\alpha \alpha)^{\mathrm{th}}\right\}\right.$ (Fig. 1) (unpublished results).

As can be seen in Table 1, both the father and the mother had normal red cell indices. The $\alpha / \beta$ globin chain synthesis ratio of both parents, calculated as means of three determinations, each carried out in duplicate in different periods, was within the range found in $\alpha$-thalassemia- 2 carriers in our laboratory $(0.62-0.88)$ and below the normal values $(1.02 \pm 0.06)$. Both parents had normal transferrin saturation. $\mathrm{Hb} \mathrm{A}_{2}$ levels of the father were below the normal values.

Restriction endonuclease analysis. When normal DNA is digested with $\mathrm{Bam} \mathrm{HI}$, the duplicated $\alpha$-globin loci resides in a DNA fragment $14.0 \mathrm{~Kb}$ in length (13). In contrast, DNA from subjects heterozygous for the deletion form of $\alpha$-thalassemia- 2 produces a $\mathrm{Bam} \mathrm{HI} \alpha$-specific fragment of $10.5 \mathrm{~Kb}$ containing the single $\alpha$-locus $(-\alpha)$ in addition to the normal $14.0 \mathrm{~Kb}$ fragment. Homozygotes for the deletion form of $\alpha$-thalassemia-2 $(-\alpha /-\alpha)$ yield only the $10.5 \mathrm{~Kb}$ fragment. This pattern is also seen in subjects with the deletion form of hemoglobin $\mathrm{H}$ disease $(-\alpha /--)$. The DNA of the subject under study digested with Bam $\mathrm{HI}$ and hybridized with the $\alpha$-specific probe produced two fragments, 14.0 and $10.5 \mathrm{~Kb}$ in length. This pattern is compatible either with the heterozygous state of the deletion form $\alpha$-thalassemia-2 $(-\alpha / \alpha \alpha)$ or with a combination of the above condition and a non-deletion $\alpha$-thalassemia lesion, leaving the $\alpha$-globin structural loci intact in one of the two chromosome $16\{-\alpha\}$ $\left.(\alpha \alpha)^{\mathrm{th}}\right\}$. The DNA of the father gave the same pattern as the proband with 14.0 and $10.5 \mathrm{~Kb}$ bands whereas the DNA of the mother yields only the normal $14.0 \mathrm{~Kb}$ fragment. These results suggest that the father is a heterozygote for the deletion form $\alpha$ thalassemia-2, $(-\alpha / \alpha \alpha)$. The mother, who had a normal $\alpha$-globin gene map and an $\alpha$-thalassemia carrier phenotype, on the basis of globin chain synthesis analysis, is probably a heterozygote for a non-deletion $\alpha$-thalassemia-2 defect $\left\{\alpha \alpha /(\alpha \alpha)^{\mathrm{th}}\right\}$. These results and the hematologic data above described suggest that our proband has a form of non-deletion $\alpha$-thalassemia associated with the $\alpha$-thalassemia-2 deletion defect. His genotype should therefore be written: $\left\{-\alpha /(\alpha \alpha)^{\text {th }}\right\}$.

The molecular basis of $\alpha$-thalassemia in our case was further characterized by digestion with $B g l$ II and hybridization with the $\alpha$-specific probe (Fig. 2). Normal DNA digested with $B g l$ II yields two $\alpha$-globin specific fragments of 12.5 and $7.0 \mathrm{~Kb}$ containing the $\alpha_{2}$ and $\alpha_{1}$ globin structural loci respectively (1). Using this enzyme, it is possible to distinguish the two different mutations leading to a chromosome with a single $\alpha$-locus: leftward deletion in which the $\alpha_{2}$ globin structural locus is deleted, and rightward deletion, which results from the deletion of a DNA fragment bridging the two normal $\alpha$-globin genes. The leftward deletion haplotype, i.e., the deletion resulting from the loss of the $\alpha_{2}$ gene, yields only the $7.0 \mathrm{~Kb}$ fragment. In the rightward deletion a 16.0 $\mathrm{Kb}$ fragment replaces the two normal fragments (1). In the subject under study we found the $7.0,12.5$ and $16.0 \mathrm{~Kb}$ fragments. This pattern is compatible with the rightward deletion $\alpha$ thalassemia-2 genotype $(-\alpha / \alpha \alpha)$ or with the combination of the rightward deletion $(-\alpha)$ and a non-deletion defect $\left\{(\alpha \alpha)^{\text {th }}\right\}$. The DNA of the father gave the same pattern as the proband whereas in the mother a normal pattern was detected.

Further characterization of the molecular defect was carried out by digestion of DNA with $B g l$ II and hybridization of the DNA fragments with a $\zeta$-specific probe. Normal DNA $(\alpha \alpha / \alpha \alpha)$ digested with $B g l$ II yields two fragments of 12.0 and $11.0 \mathrm{~Kb}$ containing the $\psi \zeta$ and $\zeta_{2}$ gene respectively $(9,19)$. $\alpha$-Thalassemia2 carriers with a single $\alpha$-gene deleted show a different pattern

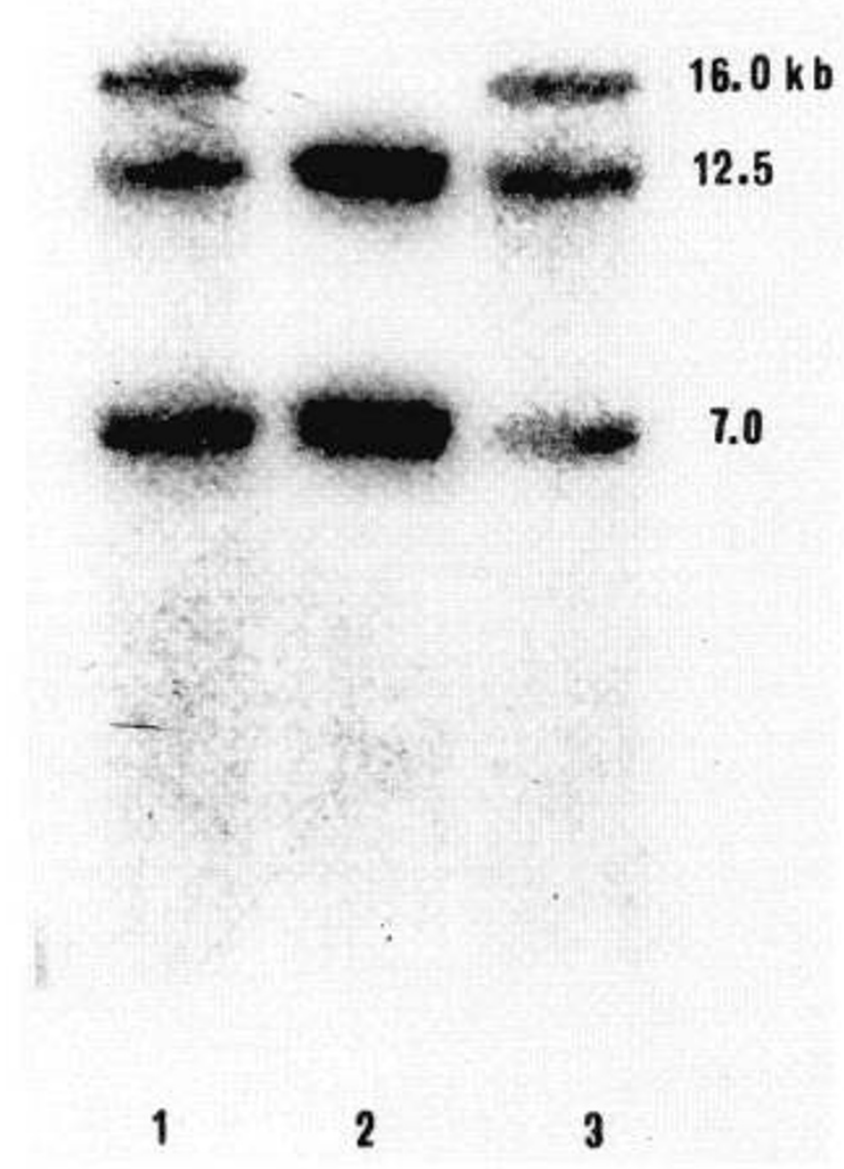

Fig. 2. Blot hybridization of DNA restricted with $B g / \mathrm{II}$ and hybridized with an $\alpha$-globin gene specific probe: lane 1: patient M. L., lane 2: mother, and lane 3 father.

according to the type of crossing over producing the single $\alpha$ locus (1). In the rightward deletion, more commonly seen in Mediterraneans, the normal $11.0 \mathrm{~Kb}$ fragment is associated with a new fragment $16.0 \mathrm{~Kb}$ in length. Digestion with $\mathrm{Bgl} \mathrm{II}$ and hybridization with $\zeta$-specific probes consent the identification of the haplotypes in which both $\alpha$-globin structural genes are deleted. In fetal hydrops, in which there is a deletion of all four $\alpha$ globin structural loci, two different molecular lesions have been found. In South Asian patients with this condition the residual $\zeta_{2}$ gene is contained in a $10.5 \mathrm{~Kb} \zeta$-specific fragment $\left(-{ }_{-} \mathrm{SEA} /\right.$ - SEA $_{\text {SE }}$ whereas in Mediterranean patients it is associated with a $13.9 \mathrm{~Kb}$ fragment (- $\left.-^{\text {Med }} /-^{\text {Med }}\right)(19)$. DNA from our patient gives a $16.0 \mathrm{~Kb}$ fragment in addition to the normal 11.0 and $12.0 \mathrm{~Kb}$ fragments. This pattern, indicative of the rightward $\alpha$-thalassemia- 2 condition, is again compatible either with $(-\alpha / \alpha \alpha)$ or with $\left\{-\alpha /(\alpha \alpha)^{\text {th }}\right\}$ genotypes and definitively excludes the $(-\alpha /--)$ genotype.

The DNA from the father yields a $11.0,12.0$, and $16.0 \mathrm{~Kb}$ fragments as the proband, and that of the mother a normal pattern.

As controls, we analyzed DNA from six infants with $1-2 \% \mathrm{Hb}$ Bart's, six with 5-6\%, one with $25 \%$ and 8 with no Hb Bart's at birth. Infants with $1-2 \%$ Hb Bart's showed the restriction pattern compatible with the deletion of one $\alpha$-globin structural gene $(-\alpha / \alpha \alpha)$, those with $5-6 \%$ were found to have the deletion of one $\alpha$-globin locus from each chromosome $(-\alpha /-\alpha)$, the only infant with $25 \%$ had the deletion of 3 of the $4 \alpha$-structural genes $(-\alpha /--)$ and those infants with no Hb Bart's had a full complement of four $\alpha$-globin genes, according to previous studies $(4,10,12)$. 


\section{DISCUSSION}

The hematologic and gene analysis data presented here provide strong evidence that our subject with $16 \% \mathrm{Hb}$ Bart's at birth and an $\alpha$-thalassemia carrier-like condition at follow-up is a genetic compound for deletion $\alpha$-thalassemia-2 $(-\alpha)$ and a non-deletion $\alpha$-thalassemia determinant $\left\{(\alpha \alpha)^{\mathrm{th}}\right\}$. He definitively inherited a haplotype with a single $\alpha$-globin gene $(-\alpha)$ from his father. His mother had a normal $\alpha$-globin restriction map and a globin chain synthesis ratio repeatedly in the $\alpha$-thalassemia- 2 carrier range, in the absence of no other obvious causes, including iron deficiency, of her globin chain imbalance. She should, therefore, have one chromosome with two normal $\alpha$-globin structural genes and one chromosome with a non-deletion $\alpha$-thalassemia- 2 determinant She could have transmitted to her child, who showed a restriction map typical of a single $\alpha$-globin gene deleted, either the normal chromosome or the chromosome with the $\alpha$-thalassemia-2 determinant. But the phenotype of the proband at birth, with very marked microcytosis and $\mathrm{Hb}$ Bart's levels completely outside the range shown in the $(-\alpha /-\alpha)$ genotype $(4.20 \pm 0.9)$, is not compatible with the $(-\alpha / \alpha \alpha)$ genotype, and suggest that he inherited from his mother the non-deletion $\alpha$-thalassemia-2 chromosome $\left\{(\alpha \alpha)^{\mathrm{th}}\right\}$. The development of neonatal jaundice cannot be certainly ascribed to the $\alpha$-thalassemia condition, as more severe $\alpha$ thalassemia defects, such as $\mathrm{HbH}$ disease are usually non-associated with neonatal hyperbilirubinemia (unpublished observations).

This non-deletion $\alpha$-thalassemia determinant produces, especially in the neonatal period, a more severe phenotype than that resulting from the deletion $\alpha$-thalassemia-2 lesion. It is obviously milder than the $\alpha$-thalassemia-1 lesion (- $)$, as it does not result in a complete suppression of $\alpha$-globin chain synthesis. In fact, subjects, who are homozygous for the $\alpha$-thalassemia- 2 deletion defect $(-\alpha /-\alpha)$ or heterozygous for the $\alpha$-thalassemia- 1 determinant $(--/ \alpha \alpha)$, have less severe hypocromia and microcytosis and lower levels of Hb Bart's $(4.20 \pm 0.09)$ in their cord blood than our patient. After the first 5-9 months of life when Hb Bart's levels decrease to low values, the clinical phenotype produced by this genotype $\left\{-\alpha /(\alpha \alpha)^{\mathrm{th}}\right\}$ overlaps with that resulting from the $(-$ $\alpha /-\alpha)$ genotype. The more expressed phenotype at birth found in our case is not surprising because the imbalance of globin chains is always magnified at birth, as is exemplified by the $(-\alpha / \alpha \alpha)$ genotype, who frequently showed $1-2 \% \mathrm{Hb}$ Bart's at birth and is usually hematologically silent later on.

Our conclusions are supported by a study of the $\mathrm{HbH}$ disease phenotype-genotype correlation in the same Sardinian population, in which the non-deletion $\mathrm{HbH}$ disease patients $\left\{--/(\alpha \alpha)^{\mathrm{th}}\right\}$ were found to have a much more severe phenotype than that seen in patients with the deletion $\mathrm{HbH}$ disease $(-\alpha /--)$ genotype (unpublished results). The non-deletion chromosome $\left\{(\alpha \alpha)^{\text {th }}\right\}$, therefore, should contain two $\alpha$-globin genes that are less active than a single gene $(-\alpha)$. In the heterozygous states the deletion $\alpha$ thalassemia-2 $(-\alpha / \alpha \alpha)$ and the non-deletion determinant $\{\alpha \alpha\}$ $\left.(\alpha \alpha)^{\text {th }}\right\}$ cannot be distinguished as they give overlapping hematologic features (unpublished results).

A non-deletion determinant producing, in the homozygous state, $\mathrm{HbH}$ disease has been recently characterized in Saudi Arabians (17). This determinant in combination with a chromosome bearing a single $\alpha$-locus was seen to produce a hematologic phenotype slightly more severe than that resulting from the $(-\alpha /-\alpha)$ genotype. This genetic pattern suggests that the Saudi Arabians non-deletion $\alpha$-thalassemia determinant might have a more severe phenotypic effect than that seen in Sardinians. Nondeletion $\alpha$-thalassemia is probably highly heterogeneous in different and even within the same population (5). Gene sequencing of the DNA from non-deletion $\mathrm{HbH}$ disease patients have recently defined two different lesions not due to gross gene deletion, i.e. five base pair deletion in the first intervening sequence of the $\alpha_{2}$ gene and single nucleotide mutation in the coding region of the $\alpha_{2}$ gene $\left(\alpha^{125 \text { Leu } \rightarrow \text { Pro }}\right)(3,16)$.
Cord blood screening is frequently performed in the offsprings of couples at risk to produce $\alpha$-thalassemia. Although $\mathrm{HbH}$ disease in newborns is usually associated with $\mathrm{Hb}$ Bart's levels higher than 18\% [see Weatherall and Clegg, 1981 (22) and our unpublished observations], the finding of moderate increase of Hb Bart's, on the order of 16-18\%, does not allow the prediction of a certain phenotype, being compatible either with the development of $\mathrm{HbH}$ disease or with a much less severe thalassemia defect, such as has been found in the patient hereby described.

Restriction endonuclease analysis could distinguish these conditions, thus permitting a more accurate counseling.

There are many different deletion and non-deletion lesions within the $\alpha-\zeta$ globin gene complex which result in many different types of $\alpha$-thalassemias. Further research is needed in order to better define the phenotype-genotype correlations of these extremely heterogeneous group of genetic disorders.

\section{REFERENCES AND NOTES}

1. Embury, S. H., Miller, J. A., Dozy, A. M., Kan, Y. W., Chang, V., and Todd, D.: Two different molecular organizations account for the single $\alpha$-globin gene of the $\alpha$-thalassemia-2 genotype. J. Clin. Invest. 66: 1319 (1980).

2. Galanello, R., Diana, G., Furbetta, M., Angius, A., Melis, M. A., Rosatelli, C. and Cao, A.: $\alpha$-thalassemia in Sardinian infants. J. Med. Genet., 17: 357 (1980).

3. Goossens, M., Lee, K. Y., Liebhaber, S. A., and Kan. Y. W.: Globin structural mutant $\alpha^{12 s}$ Leu $\rightarrow$ Pro. a novel cause of $\alpha$-thalassemia. Nature 296: 864 (1982).

4. Higgs, D. R., Pressley, L., Clegg, J. B., Weatherall, D. J., Higgs, S., Carey, P.. and Serjeant, R.: Detection of $\alpha$-thalassemia in Negro infants. Br. J. Hematol., 46: 39 (1980)

5. Higgs, D. R., Pressley, L., Aldridge, B.. Clegg, J. B., Weatherall. D. J., Cao, A. Hadjiminas, M. G., Kattamis, C. Metaxatou-Mavromati, A., Rachmilewitz. E.. and Sophocleous, T.: Genetic and molecular diversity in non-deletion $\mathrm{HbH}$ disease. Proc. Natl. Acad. Sci. USA, $78: 5833$ (1981).

6. Huisman, T. H. J., Schroeder, W. A.. Brodie, A. N.. Mayson, S. M., and Jakway, J.: Microchromatography of haemoglobins. III. A simplified mcthod for the determination of hemoglobin $A_{2}$. J. Lab. Clin. Med., 86: 700 ( i 975 ).

7. Kan, Y. W., Schwartz. E., and Nathan. D. G.: Globin chain synthesis in the alpha thalassemia syndromes. J. Clin. Invest., 47: 2515 (1968).

8. Kan, Y. W., Dozy, A. M., Trecartin, R., and Todd, D.: Identification of a nondeletion defect in $(\gamma$-thalassemia. N. Engl. J. Med., 297: 1081 (1977).

9. Lauer. J.. Shen, C. L., and Maniatis, T.: The chromosomal arrangement of human $\alpha$-like globin genes: sequence homology and $\alpha$-globin gene deletions. Cell, 20: $119(1980)$.

10. Lie-Injio, L. E.. Solai, A.. Herrera, A. R., Nicolaisen, L. Kan, Y. W. Wan. W. P., and Hasan, K.: Hb Bart's level in cord blood and deletions of ( $\alpha$ globin genes. Blood, 59: 370 (1982).

11. Maniatis, T., Jeffrey, A., and Kleid. D. G.: Nucleotide sequence of the rightward operation of phage. Proc. Natl. Acad. Sci. USA, 72: 1184 (1975).

12. Ohene-Frempong, K., Rappaport. E.. Atwater, J., Schwartz, E., and Surrey, S. Alpha gene deletions in Black newborn infants with Hb Bart's. Blood. 56 : $931(1980)$.

13. Orkin, S. H.: The duplicated human $\alpha$-globin genes lie close together in cellular DNA. Proc. Natl. Acad. Sci. USA, 75: 5950 (1978).

14. Orkin. S. H., Old, I., Lazarus, H.. Altay, C.. Gurgey, A. Weatherall, D J., and Nathan, D. G.: The molecular basis of $\alpha$-thalassemias: frequent occurrence of disfunctional $\alpha$-loci among non-asian with $\mathrm{HbH}$ disease. Cell, 17: 33 (1979)

15. Orkin. S. H. and Michelson, A.: Partial deletion of the $\alpha$-globin structural gene in human $\alpha$-thalassemia. Nature. 286:538 (1980).

16. Orkin, S. H.. Goff, S. C., and Hechtman. R. L.: Mutation in an intervening sequence splice junction in man. Proc. Natl. Acad. Sci. USA 78: 5041 (1981).

17. Pressley, L., Higgs, D. R., Clegg, J. B., Perrine, R. P., Pembrey, M. E., and Weatherall. D. J.: A new genetic basis for hemoglobin-H disease. N. Engl. J. Med., 303: 1383 (1980).

18. Pressley, L., Higgs, D. R., Aldridge, B., Metaxatau-Mavromati, A., Clegg, J. B.. and Weatherall, D. J.: Characterization of a new $\alpha$-thalassemia- 1 defect due to a partial deletion of the $(\mathrm{r}$-globin gene complex. Nucleid Acid Res. 8: 4889 (1980).

19. Pressley, L., Higgs, D. R., Clegg. J. B., and Weatherall, D. J.: Gene deletions in $\alpha$-thalassemia prove that the $5^{\prime} \zeta$ locus is functional. Proc. Natl. Acad. Sci. USA. 77: 3586 (1980)

20. Proudfoot, N., Shander. M., Woude, S. V., and Maniatis, T.: The structure and transcription of normal and abnormal human globin genes. J. Supramol. Struc. and Cell Biochem. Supp., 5: 381 (1981).

21. Southern, E. M.: Detection of specific sequences among DNA fragments separated by gel electrophoresis. J. Mol. Biol.. 98: 503 (1975).

22. Weatherall, D. J. and Clegg, J. B.: The thalassemia syndromes. 3rd edn. (Blackwell Scientific Publications, Oxford, 1981).

23. Wilson, J. T., Wilson, L. B., De Riel, J. K., Villa-Komaroff, L., Efstratiadis, A., Forget. B. G. and Weissman. S. M.: Insertion of synthetic copies of human globin genes into bacterial plasmids. Nucleid Acid Res.. 5; 563 (1978). 
24. On leave at the Howard Hughes Medical Institute, Laboratory and the Department of Medicine, University of California, San Francisco, USA.

25. We are grateful to Dr. Y. W. Kan for his continuing advice and Rita Loi for editorial assistance. We would also like to thank Dr. B. Forget for the plasmid JW-101 and Drs. J. Lauer and $\mathrm{T}$. Maniatis for plasmid pBR Y.

26. Requests for reprints should be addressed to: Professor Antonio Cao, Istituto di Clinica e Biologia dell'Età Evolutiva. Università degli Studi di Cagliari. c/o Ospedale Regionale delle Microcitemie, Via Jenner, (Casella Postale 251),
09100 Cagliari, Sardinia, Italy

27. This work was supported by grants from Assessorato Igiene e Sanità Regione Autonoma della Sardegna (progetto 833). The National Institute of Health (HL-24173-03). Program of Preventive Medicine CNR (Rome. Italy) Project M.E.E. n. 8136.83 and CNR Institute for the Study of Thalassemia and Mediterranean Anemias, Cagliari.

28. Received for publication August 3,1982

29. Accepted for publication March 30, 1983.

\title{
Plasma and Red Blood Cell Fatty Acid Composition in Children with Protein-Calorie Malnutrition
}

\author{
JON A. WOLFF. ${ }^{(47)}$ SIMEON MARGOLIS, KATALIN BUJDOSO-WOLFF, EDWARD MATUSICK, \\ AND WILLIAM C. MACLEAN, JR. \\ Department of International Health. The Johns Hopkins University School of Hygiene and Public Health \\ [J.A.W., K.B.W.] Department of Medicine, The Johns Hopkins University School of Medicine, Bultimore, \\ Maryland /S.M.J: Ross Laboratories Columbus, Ohio: Lipid Laboratory, Beltsville Human Nutrition Research \\ Institute, Beltsville, Maryland, USA /W.C.M.J
}

\begin{abstract}
Summary
Plasma and red cell fatty acids were measured in 44 children with third degree malnutrition: 22 children with marasmus, 11 children with kwashiorkor, and 11 with marasmic kwashiorkor (MK). The presence of edema, dermatosis, hair changes, and hypoalbuminemia were positively correlated with the red cell percentage linoleic acid and negatively correlated with red cell percentage arachidonic acid. Red cell percentage linoleic acid in kwashiorkor was decreased from the control value of $15.3 \%$ to $10.9 \%$. In marasmus and MK, there were significantly greater decreases, to $7.7 \%$ and $\mathbf{8 . 0} \%$, respectively. Red cell arachidonic acid in kwashiorkor was significantly $(P<0.001)$ decreased to $\mathbf{9 . 8 \%}$ (control value of $13.1 \%$ ) whereas in marasmus there was no significant change. Only one sample, plasma from an infant with marasmus, had any detectable eicosatrienoic acid $(20: 3, \omega 9)$. Similar changes in fatty acid composition have been reported in infants with acrodermatitis enteropathica, in an infant with biotin deficiency, and in biotin-deficient rats.
\end{abstract}

\section{Abbreviations}

EFA, essential fatty acid

MK, marasmic kwashiorkor

PCM, protein-calorie malnutrition

$\mathrm{RBC}$, red blood cell

PCM encompasses three clinical syndromes: kwashiorkor, marasmus, and MK. Kwashiorkor is characterized by edema, dermatosis, enlarged fatty liver, changes in hair pigment and texture, and decreased serum albumin in the presence of normal subcutaneous fat. Marasmic infants are generally younger and lack any specific physical or laboratory findings other than wasting of muscles and decreased subcutaneous fat. Many infants with marasmus exhibit some, but not all, of the signs of kwa- shiorkor and are designated MK. The McLaren score has proven useful in differentiating among the three syndromes (25).

The etiology and pathogenesis of the forms of PCM remain unclear. Animals fed a high carbohydrate, low protein diet often develop kwashiorkor. Those on a low carbohydrate, low protein diet exhibit marasmus. Studies comparing the dietary histories of infants with kwashiorkor and marasmus frequently failed to show any such dietary correlation (27). Even so, protein deficiency could explain some of the findings in kwashiorkor. The edema of kwashiorkor results, in part, from the low serum albumin concentration, and the fatty liver is felt to be the result of decreased lipoprotein synthesis $(6,15,22,35,42)$.

The dermatosis of kwashiorkor may be the result of tryptophan deficiency because it resembles the dermatosis in pellagra. Human EFA deficiency also causes a desquamative dry dermatosis, as well as retarded growth. A scaly dermatosis with increased skin permeability, depigmentation, fatty lung, and fatty liver was documented in EFA-deficient animals (2). Naismith (27) suggested that EFA deficiency occurs in kwashiorkor. He showed that the weaning foods of children with kwashiorkor in Nigeria contained less than minimum recommended intake of linoleic acid $(<1 \%$ of total energy intake). Plasmic linoleic and arachidonic acid levels were decreased, whereas the concentration of eicosatrienoic acid, an abnormal fatty acid, was increased; thus satisfying Holman's criterion for EFA deficiency (an eicosatrienoic to arachidonic acid ratio of $>0.4)(16,17)$. Other studies on children with kwashiorkor also have reported a decrease in the ratio of unsaturated to saturated fats in plasma $(22,35)$ and in red cell lipids (32).

Previous studies evaluated EFAs in kwashiorkor only. In the present study, a broader spectrum of malnutrition was studied in order to understand the peculiar features of kwashiorkor. Plasma lipids reflect changes in diet over a few days. Red cell lipids were measured because they reflect changes in lipid concentration and diet over a few weeks (11). Red cell lipids should 